\title{
Investigation on the Changes in the Temperature that is Caused in Vortex Tube
}

\author{
Ünal UYSAL*, Selahattin KASAR** \\ *Sakarya Üniversitesi Mühendislik Fakültesi Makine Mühendisliği Bölümü, 54050 Sakarya \\ E-mail: uysal@sakarya.edu.tr \\ *Sakarya Üniversitesi Fen Bilimleri Enstitüsü Makine Mühendisliği Bölümü, 54050 Sakarya \\ E-mail: salah.kassar@ogr.sakarya.edu.tr
}

\begin{abstract}
This paper presents effect of cold mass friction, the rates of air flow, the inlet pressure, and the time on hot and cold air temperatures that are generated in the vortex tube. The vortex tube is manufactured by simple equipments within low prices. That proves the simplification of the vortex tube. Although the efficiency of vortex tube is low, but it produces low temperatures without using expensive cooling machines.
\end{abstract}

Keywords: Vortex tube; cold and hot air temperatures cold mass fraction.

\section{Introduction}

Vortex tube, also called Ranque and Hilsch tube (RHVT) who started creating and developing it, is a device with a simple structure and wide applications. It can separate a compressed stream into hot and cold streams. Vortex tube was discovered by Ranque. He got a French patent for the device in 1932, United States patent in 1934. The phenomenon of the temperature or energy separation in a RHVT was unexpectedly discovered by Ranque when he experimentally studied on the cyclone duct separator. Then, Hilsch improved the performance of the RHVT by adjusting the tube geometrical and inlet pressure conditions. After World War II, tubes and research that belong to Hilsch has been reveled and studied widely. Westley made more than 100 researches and references about the Vortex Tube. At the same time, there are a lot of articles that are made by many researchers for example: Nash, Dobratz, Kalvinskas, McGree, and Curley. And these articles unleash Vortex tubes to be used in more applications and to be more improved.

$\begin{array}{llll}M_{c} & \text { Cold mass flow rate }\left(\mathrm{m}^{3} / \mathrm{h}\right) & T_{i} & \text { Inlet temperature }\left({ }^{\circ} \mathrm{C}\right) \\ M_{i} & \text { Inlet mass flow rate }\left(\mathrm{m}^{3} / \mathrm{h}\right) & D_{c} & \text { Diameter of cold tube }(\mathrm{mm}) \\ \Delta T & \text { Temperature difference }\left({ }^{\circ} \mathrm{C}\right) & D_{h} & \text { Diameter of hot tube }(\mathrm{mm}) \\ \Delta T_{c} & \text { Cold temperature difference }\left({ }^{\circ} \mathrm{C}\right) & D_{i n} & \text { Inner diameter of vortex tube }(\mathrm{mm}) \\ \Delta T_{h} & \text { Hot temperature difference }\left({ }^{\circ} \mathrm{C}\right) & P_{i} & \text { Inlet pressure }(\text { bar }) \\ T_{c} & \text { Cold temperature }\left({ }^{\circ} \mathrm{C}\right) & \mu_{c} & \text { Cold mass fraction } \\ T_{h} & \text { Hot temperature }\left({ }^{\circ} \mathrm{C}\right) & & \end{array}$

\footnotetext{
*Corresponding author: Address: Faculty of Engineering, Department of Mechanical Engineering Sakarya University, 54050, Sakarya TURKEY. E-mail address: uysal@sakarya.edu.tr, Phone: +905327824672
} 


\section{Review of the previous researches that relate to Vortex Tube}

In the past, there were interests in the vortex flows because it is used in some industrial applications (ovens and burners of gas turbines). By using Vortex Tube, we will get a cold and a hot flows at the same time. Vortex Tube is used frequently in the industrial applications for heating and cooling process and it's considered as a simple, small, and quiet device. Many researchers make a great efforts to demonstrate the phenomena that happens during the process of separating the energy inside the Vortex Tube. Many research studied this phenomena that are divided into two parts. The first one is used experimental studies, by this way a lot of phenomena are interpreted. The second one is used numerical and analytical studies that help to reveal the processes that happen inside the tube.

The Ranque-Hilsch vortex tube (RHVT) is a small interesting extraordinary mechanical device used as refrigeration machine. The vortex tube was first discovered by French physicist Georges Ranque [1,2]. Ranque and Hilsch first studied vortex tube and its ability to create a temperature difference in 1933 and 1947. Vortex tube converts compressed air into two distinct streams of air; the first one has a low temperature and the other has a high temperature. Vortex tubes in general consists of inlet nozzle, vortex chamber, orifice, hot air exit, hot control valve and cold air exit. The compressed air enters through inlet nozzle and partially escaped from a hot exit at high temperature and the remaining air comes out through cold end at low temperature.

Because of the drop of efficiency of a vortex tube Hilsch had come and made several experiments considering geometrical parameters and physical properties to improve the performance of vortex tube [3]. After Hilsch, an experimental study was made by Scheper [4]. He measured the gradation of the speed, and pressure and the static and total temperature inside the vortex tube. Yunpeng Xue, Mehdi Jafarian [5], and others studied the process of temperature separation in a Ranque-Hilsch vortex tube. They made their experiments to compare the temperature drops in vortex tubes using different working fluids. They noticed that the lowest temperature within a vortex tube occurred in the central region near the injection (low pressure region). Then, they observed that the cooling performance of Helium and Argon are superior to those of other working fluids(Air, $\mathrm{N}_{2}, \mathrm{CO}_{2}, \mathrm{NH}_{3}$ ); whereas, under the same conditions, the efficiency of Helium in a Joule-Thomson expansion process is better than others. Aydin and Baki [6] studied experimentally the energy separation in counter-vortex tube. They improved the geometrical shape of the vortex tube, so it will help to increase the temperature difference to maximum value between the inlet temperature and the temperature of the cold orifice by modifying the tube dimensions, tube length, diameter of entrance orifice, and degree of the control valve. In addition, they studied effect of the inlet pressures and types of gases (Air, Oxygen, and Nitrogen) on the heat difference inside the tube. They concluded that optimum values of the angle of the control valve, the length of the pipe, and the diameter of the inlet nozzle are obtained to occur approximately in the ranges of $\mu_{c}=0.5, L / D=20, d / D=1 / 3$, which are expected to be useful for vortex tube applications. Nimbalkar and Muller [7] used in their experiments an internal diameter $\mathrm{D}=1.905 \mathrm{~cm}$ and a length $\mathrm{L}=25.4 \mathrm{~cm}(\mathrm{~L} / \mathrm{D}$ ratio equal to 13.33$)$. The tube was made of stainless steel and thermally insulated from the atmosphere to avoid errors due to heat conduction and to maintain repeatable steady-state. They conclude that the experimental results indicate that there is an optimum diameter of cold-end orifice to achieve the maximum energy separation. It was observed that for cold fraction $60 \%$, the effect of cold end orifice 
diameter is negligible and above $60 \%$ of cold fraction it becomes prominent. The results also show that the maximum value of performance factor was always reachable at a $60 \%$ cold fraction irrespective of the orifice diameter and the inlet pressure. Gord and Sadi [8] assured that the inlet nozzle plays an important role to get the best performance of Vortex Tube. They concluded that the highest efficiency has been attained for cold orifice ratio of 0.64 . Smaller cold orifice ratio would give higher back pressure in the VT and which resulted in low efficiency. Larger cold orifice ratio would tend to draw flow directly from the inlet and yield weaker swirl velocities in the VT, resulting again in low efficiency. Rafiee and Sadeghiazad [9] designed a different shapes of control valves. Four different control valves (spherical, plate shape, cone shaped and truncated cone) have been manufactured for the tests. The hot control valve can manage and control the pressure at the hot side to correspond with the flow ratio for both of the streams (cold and hot). Using 3 inlet nozzles and 2.5 bar of pressure in the cold of fraction 50 $70 \%$, they found that the best shape of the control valve is truncated cone valve then Spherical control valve. Saidi and Valipour [10] found that the nozzle with three intakes shows better performance than four intakes nozzle from the point of view of refrigeration efficiency. They also conclude that the cold temperature difference and efficiency decrease by increasing the air moisture content of the air. N. Li, Z.Y. Zeng and others [11] presented an explanation for the maximum cooling effect and the maximum heating effect when the cold mass fraction is about 0.3 and 0.8 , respectively. They noticed that the cold outlet temperature increases as the cold mass fraction decreases. The combined effect makes the maximum cooling effect $\Delta$ Tc be obtained when the cold flow ratio is about 0.31. Pouraria, Kia and others [12] used two hundred and ninety six experimental data. The internal diameter of the vortex tube was $2 \mathrm{~mm}$, the cold outlet diameter was $0.25 \mathrm{D}, 0.4 \mathrm{D}$, and $0.55 \mathrm{D}$, and the length of the vortex tube $(\mathrm{L})$ was $10 \mathrm{D}$, $30 \mathrm{D}$, and 50D, respectively. The vortex tube consisted of four inlet nozzles and the angle of the control valve was fixed at $60^{\circ}$. According to the numerical results, for a vortex tube with $\mathrm{d} / \mathrm{D}=$ 0.5 , the cooling performance reaches its maximum value. Therefore, it can be concluded that the best cooling performance of the vortex tube occurs at around $\mathrm{L} / \mathrm{D}=60$. The main results obtained were summarized by Rahbar, Taherian and others [13], the maximum cold temperature and the maximum efficiency are happened at the cold mass fraction $=0.58$, and the maximum refrigeration power is achieved at the cold mass friction $=0.65$. The tangential velocity near the inlet-zone is greater than other zones. The refrigeration capacity is approximately independent of the tube-length for the values of cold-mass ratio smaller than 0.35. Cebeci and others [14] used the oxygen as a fluid and they found that the cold outlet temperature $T_{c}$ is decreased by increasing the inlet pressure for each of the nozzles. The minimum cold outlet temperatures are obtained and $P_{i}=700 \mathrm{Kpa}$ for oxygen with PP (polyamide plastic) and Al (Aluminum). The measured minimum cold outlet temperature for AL was $T_{c}=239.95 \mathrm{~K}$ and for PP is $T_{c}=253.35 \mathrm{~K}$. Majidi and others' study [15] examines different arrangements of vortex tubes (VTs) to get higher performances for cooling and heating. Their experiment includes vortex tubes. The obtained results and the studies that they have reached helped them to find out a better VTs' performance. Adity kumar and other's study [16] focused on both temperature and relative humidity separation in vortex tube within insulation and without insulation on vortex tube. They found that the best value of cold temperature drop is observed $\left[15-20{ }^{\circ} \mathrm{C}\right]$ at 0.4 cold friction, 2 bar inlet pressure, and within and without insulation. Also, the repeat the experience several times with different inlet pressure and they noticed that the best value of 
cold temperature drops are $32^{\circ} \mathrm{C}, 29^{\circ} \mathrm{C}, 26^{\circ} \mathrm{C}$ at 5 bar, 4 bar, 3 bar pressure respectively. In addition, the hot end temperature drop increases for whole range of cold mass fraction for noninsulated case. But, it's noticed that there is an increase the temperature drop at the value 0.65 0.75. Then it starts decreasing in high values of clod mass friction, for the insulated case. Yunpeng Xue and others [17] studied the flow behavior inside the vortex tube and the mechanism for the generation of cold and hot stream in a vortex tube. They studied the geometrical effects on the tube performance. Then, they suggested that there are different geometrical parameters effect on vortex tubes. They studied length and diameter of the tube and the ratio of tube length over diameter, shape and size of the nozzle, and cold and hot exits. When the vortex tube is shorter than the critical length, the cold flow will mix with hot flow. So, it will affect negativity on the temperature separation. Also, they assured that tube diameter is also an important factor. It could provide a perfect separation of the cold and hot regions. When the diameter of the vortex tube is so small or so large, it impacts on the temperature separation. So, there is a critical value that should be taken into consideration. In addition, they suggested that a short conical vortex tube can still perform well with regard to the extent of the temperature separation. Vortex angle and strong swirling flow impact on temperature drop and temperature rise. So, the decrease of tangential velocity is one of reasons for the reduction of temperature in a vortex tube.

\section{Introduction of experimental setup:}

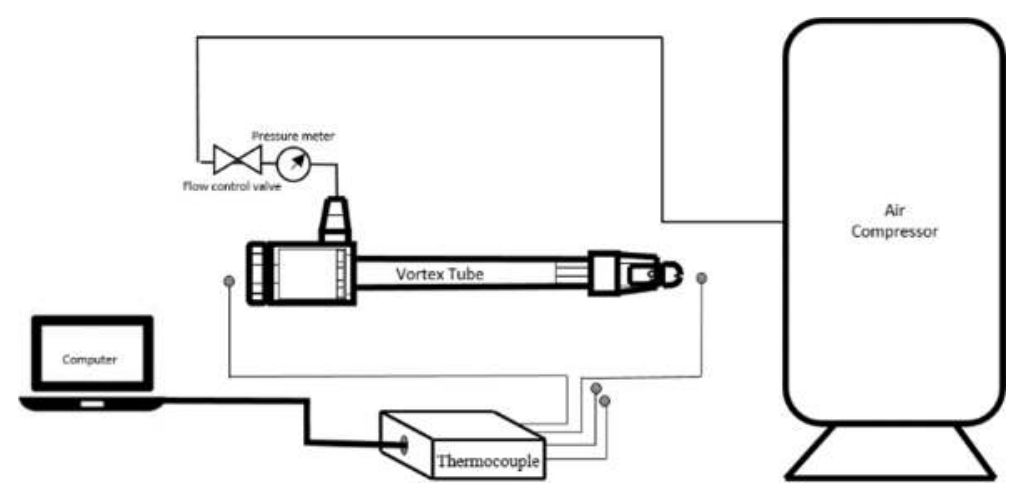

Fig. 1 Schematic diagram of experimental apparatus.

Fig. 1 shows the schematic diagram of the experimental apparatus. The compressed working fluid supplied from the compressor passes through the pressure tank with 1500L of volume, the valve where its mass rate is regulated. Inlet pressure is read by the manometer. In this experimental test run, there are two type of vortex tube; a large tube (Model 1) and a small one (Model 2). The Model 1 is characterized with the inner tube diameter of $9.7 \mathrm{~mm}$ and length of $100 \mathrm{~mm}$ and the second one is characterized with the inner tube diameter of $8 \mathrm{~mm}$ and length of $76 \mathrm{~mm}$ that were made of stainless steel which can be divided into two sections; one is the hot air tube. The other is the cold air tube. The mass flow rate of the inlet fluid is measured using an orifice. Then, the working fluid is introduced tangentially through the inlet of the vortex tube (4) into the vortex tube where it is expanded and separated into hot and cold air streams as can be seen in Figure. 2, Figure. 3; the cold stream in the central region flows out of the tube in the central orifice near to the entrance (2) while the hot air discharges the periphery at the far end of the tube (1). The control valve (3) may control the flow rate of the hot air. The thermocouple's 
wires are put in front of cold and hot exits, also they are put in different places of the tube's wall in order to measure the thermal gradient along the vortex tube. Measuring points sense the air temperature and convey it to numerical values that are displayed on the computer screen.

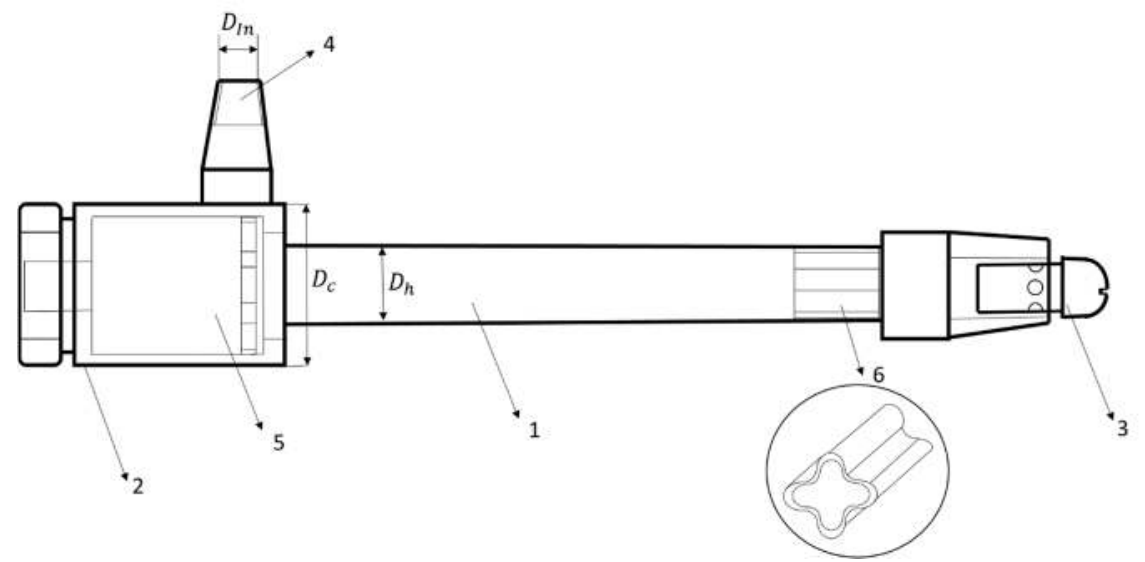

Fig.2 The structural size of Vortex Tube. Main tube (hot tube).1) Hot tube. 2) Cold tube. 3) Control valve. 4) Inlet of compressed air. 5) Generator. 6) Flow straightener

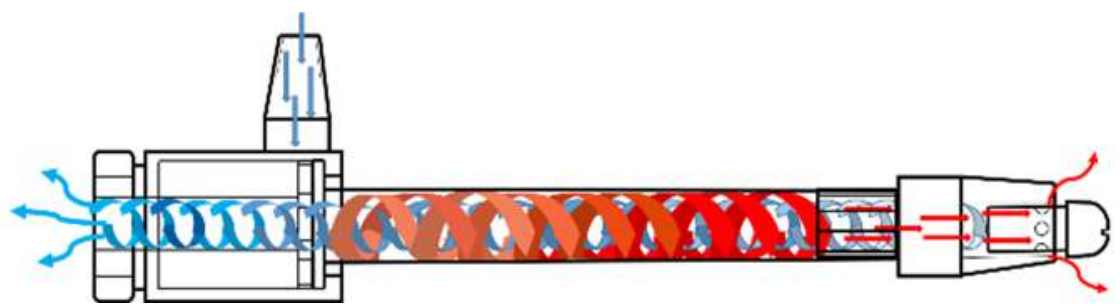

Fig. 3 The thermal separation between hot and cold air streams.

\section{Results and discussion}

The most important parameter indicating the vortex tube performance is the cold mass fraction that can be changed by adjusting the control valve, and the cold mass fraction can be expressed as:

$$
\mu_{c}=M_{c} / M_{i}
$$

Eq. (1) Cold mass fraction refers to the amount of mass flow rate of the cold air to the amount of mass flow rate of the inlet air.

In the present work, the effects of the cooling of a hot tube on the temperature reduction of the cold air of the model 1 and model 2 of counter-flow RHVT are investigated experimentally. 


\subsection{The effect of cold mass fraction on the temperature separation of the model 1 and model 2 of vortex tube}

Figure. 4(a) displays the temperature reduction in the hot tube against the cold mass fraction $\left(\mu_{c}\right)$ of model 1 and model 2 of vortex tube at 5 bar of pressure. First, the hot exit temperature difference increases with the decreases in the value of $\left(\mu_{c}\right)$. It can be observed that optimal range of $\left(\mu_{\mathrm{c}}\right)$ is between 0.4 and 0.8 . The maximum hot temperature differences have been observed $52^{\circ} \mathrm{C}$ of the model 1 at 5 bar of pressure, 0.8 of cold mass friction and $150 \mathrm{~m}^{3} / \mathrm{h}$ of air flow rate. Also, the maximum hot temperature differences have been observed $22^{\circ} \mathrm{C}$ of the model 2 at 5 bar of pressure, 0.4 of cold mass friction and $150 \mathrm{~m}^{3} / \mathrm{h}$ of air flow rate.

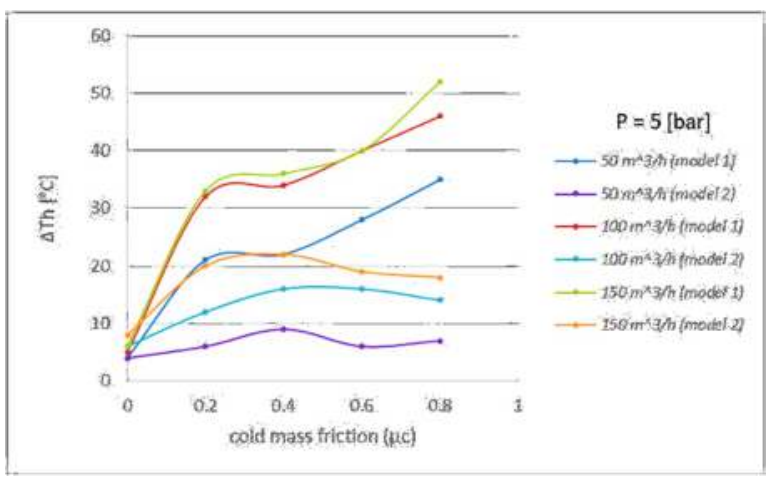

(a)

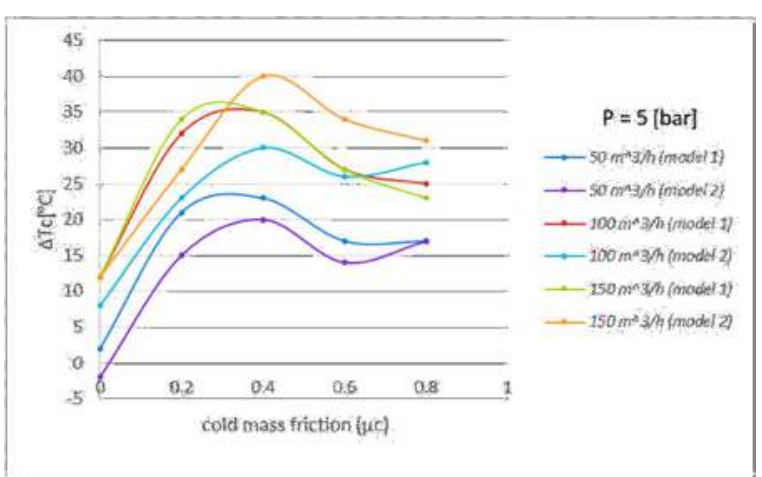

(b)

Fig. 4 The effect of cold mass fraction on the temperature separation of the model 1 and model 2 of vortex tube

The temperature reduction in the cold tube against the cold mass fraction $\left(\mu_{\mathrm{c}}\right)$ at 5 bar of pressure for model 1 and model 2 are shown in Figure. 4(b). First, the cold temperature drop increases with the increase in the value of $\left(\mu_{c}\right)$. It can be observed that optimal range of $\left(\mu_{c}\right)$ is between 0.3 and 0.4 . The maximum cold temperature drop for model 1 has been observed $36^{\circ} \mathrm{C}$ at $5 \mathrm{bar}, 150\left[\mathrm{~m}^{3} / \mathrm{h}\right]$ and 0.3 of cold mass fraction. Also, the maximum cold temperature drop for model 2 has been observed $40{ }^{\circ} \mathrm{C}$ at 5 bar, $150\left[\mathrm{~m}^{3} / \mathrm{h}\right]$ and 0.4 of cold mass fraction.

\subsection{The effect of inlet mass flow rate on the temperature separation of the model 1 and model 2 of the vortex tube}

In this experiment, it's measured both of hot and cold temperature at the end of hot and cold exists for both model 1 and model 2 of vortex tube. The amount of hot and cold air (cold mass friction) is changed by adjusting the control valve. Figure. 5(a) shows the increase of the temperature in the hot tube against air flow rate at different cold mass friction. Model 1; at $M_{i}=$ $150 \mathrm{~m}^{3} / \mathrm{h}$ and $\mu_{\mathrm{c}}=0.8$ the hot temperature is increased to become $74{ }^{\circ} \mathrm{C}$. But at the model 2; at $M_{i}=150 \mathrm{~m}^{3} / \mathrm{h}$ and $\mu_{\mathrm{c}}=0.4$ the hot temperature is increased to become $45^{\circ} \mathrm{C}$. Also, at different values of inlet mass flow rate, it's noticed that there are not a huge difference between the temperatures at specific value of cold mass friction. The temperature reduction in the cold tube against the inlet mass flow rate $M_{i}$ at different cold mass friction $\left(\mu_{\mathrm{c}}\right)$ for model 1 and 
model 2 of vortex tube are depicted in Figure 5(b). It has been noticed that the best cold temperature is $-12{ }^{\circ} \mathrm{C}$ at $M_{i}=150 \mathrm{~m}^{3} / \mathrm{h}$ of flow air and cold mass friction of $\mu_{\mathrm{c}}=0.6$ for the model 1 , but it's noticed that the best cold temperature for model 2 is $-17^{\circ} \mathrm{C}$ at $M_{i}=$ $150 \mathrm{~m}^{3} / \mathrm{h}$ of flow air and $\mu_{\mathrm{c}}=0.4$ of cold mass friction.

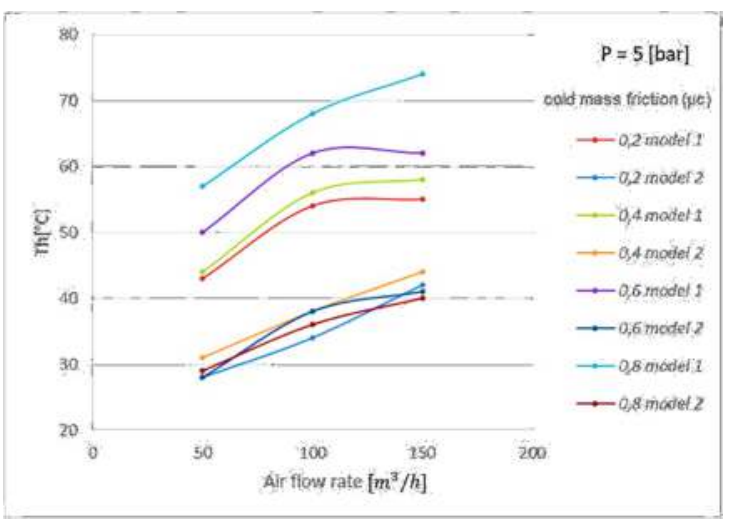

(a)

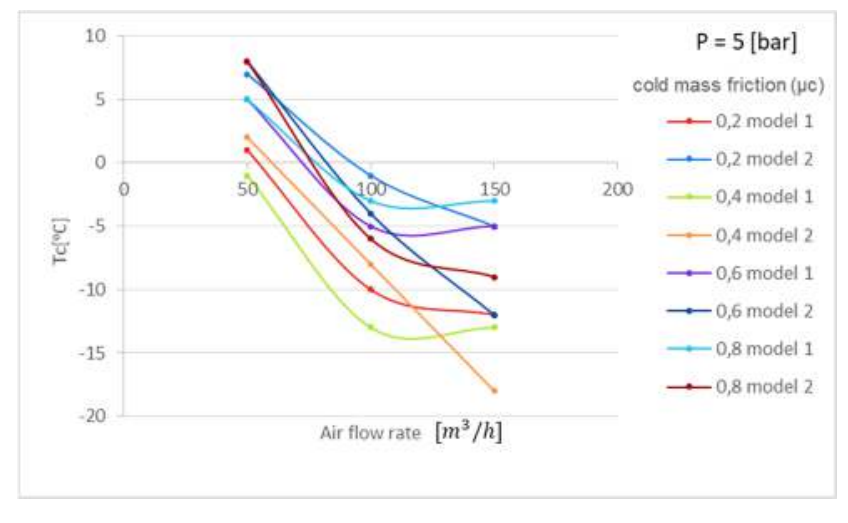

(b)

Fig. 5 The effect of inlet mass flow rate on the temperature separation of model 1 and model 2 of vortex tube

\subsection{The effect of the time on increase and drop the temperature exists at different air flow rates}

The increase and drop both of hot and cold temperature exists at different air flow rate were experimentally investigated as shown in Figure. 6. It has been observed that the cold temperature in model 1 decreases sharply at the $1^{\text {st }}$ sec to be less than -5 degree, after the $6^{\text {th }}$ sec the cold air temperatures become much cold to be less than -12 degree then the temperatures keep on its value and have a constant value approximately. In model 2 , it has been observed that the cold temperature decreases sharply at the $1^{\text {st }}$ sec like model 1 to be less than -5 degree, after that in the $6^{\text {th }}$ sec the cold air temperatures become much cold to be less than -12 degree then the temperatures continue decreasing at $13^{\text {th }}$ sec until being $(-17)$ degree and have a constant value approximately. The hot air temperature for model 1 starts with 25 degree and keeps its value till the $2^{\text {nd }} \mathrm{sec}$ then increases instantly to be at $3^{\text {rd }} \mathrm{sec}$ between $40-43^{\circ} \mathrm{C}$ then they keep on their values almost constantly. In the model 2 the hot air temperature starts at the 25 degree then increases sharply to be at $3^{\text {rd }} \mathrm{sec}$ almost 40 degree then the temperatures increase and decrease among the rate 40-45 degree. 


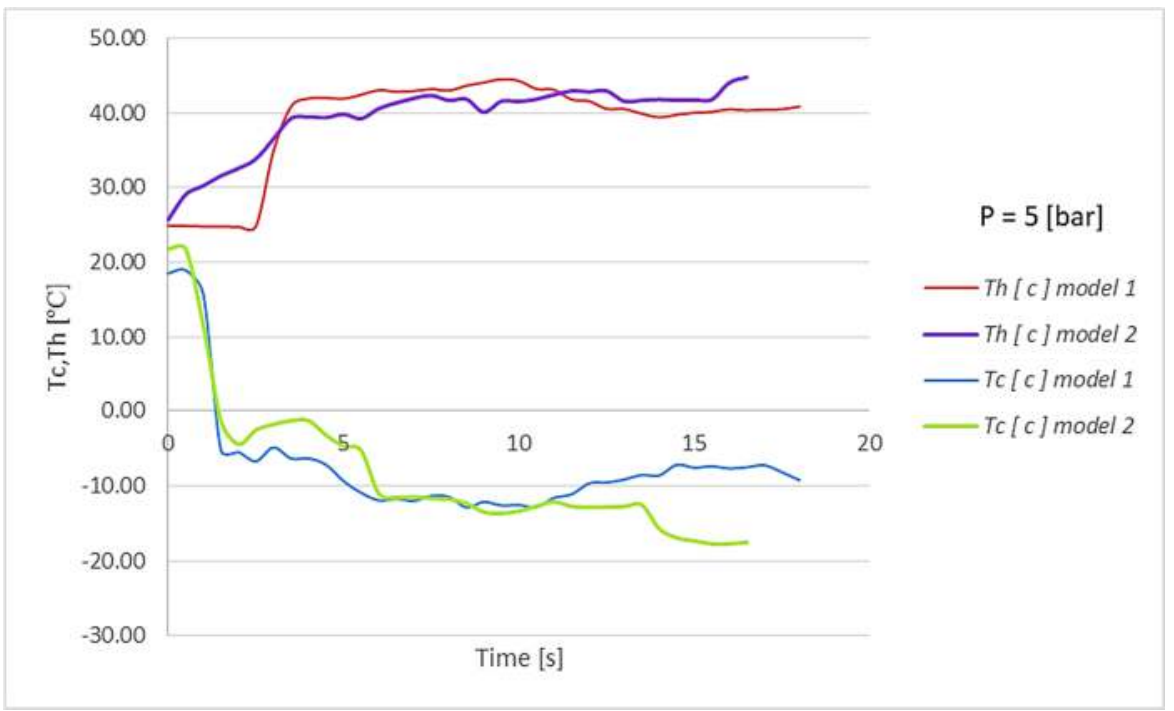

Fig. 6 The effect of the time on increase and drop the temperature exists at different air flow rates for model 1 and model 2 of vortex tube.

\section{Conclusion:}

An experimental study on the temperature separation in the vortex tube has been carried out and this research finding can be summarized as follows:

1- Vortex tube is built by simple equipments and with a low price. That proves the simplification of the vortex tube. Although the efficiency of vortex tube is low, it produces low temperatures without using expensive cooling machines.

2- As observed from the experiments; The drop of the heat on the cold side (the increase of the heat of the hot side) relates to many reasons:

- Control valve's position on the hot side (cold mass friction).

- The amount of the flow.

- Inlet pressure.

3- There is no need to have a high flow to obtain high differences of the temperature.

4- As the results, it has been observed that there were instantly increasing and decreasing of the temperature on a long the tube.

5- The best hot air temperature that could be obtained is 74 degree by model 1, but the best cold air temperature that could be obtained is -17 degree by model 2 .

\section{References:}

[1] Ranque GJ. Experiments on expansion is a vortex with simultaneous exhaust of hot air and cold air. J phys Radium (Paris) 1933;4:112-4 S-115, june. Also translated as General Electric Co., Schenectady Works Library 1947; T.F. 3294.

[2] Ranque GJ. Method and apparatus for obtaining from a fluid under pressure two outputs of fluid at different temperature. US patent 1:952,281, 1934.

[3] Hilsch R. The use of expansion of gases in a centrifugal field as a cooling process. Rev Sci Instum 1947;18(2):108-13. 
[4] Scheper GW. The vortex tube; internal flow data and a heat transfer theory. J ASRE Refrig Eng 1951;95:9859.

[5] Xue Y, Jafarian M, Choudhry A, Arjomandi M (2015) The Expansion Process in a Counter-flow Vortex Tube. J Vortex Sci Technol 2: 114.

[6] Aydin O, Baki M. An experimental study on the design parameters of a counter flow vortex tube. Energy J 2006; 31(14):2763-2772.

[7] S.U. Nimbalkar, M.R. Muller, An experimental investigation of the optimum geometry for the cold end orifice of a vortex tube. Applied Thermal Engineering 29 (2009) 509514.

[8] M. Farzaneh-Gord, M. Sadi, Improving vortex tube performance based on vortex generator design. Energy 72 (2014) 492-500.

[9] S.E. Rafiee, M.M. Sadeghiazad, Experimental and 3D CFD investigation on heat transfer and energy separation inside a counter flow vortex tube using different shapes of hot control valves. Applied Thermal Engineering 2017; 648-664.

[10] M.H. Saidi, M.S. Valipour, Experimental modeling of vortex tube refrigerator. Applied Thermal Engineering 23 (2003) 1971-1980.

[11] N. Li , Z.Y. Zeng, Z. Wang, X.H. Han , G.M. Chen, Experimental study of the energy separation in a vortex tube. International journal of refrigeration 52015; 93-101.

[12] Pouraria, H., et al. modeling the cooling performance of vortex tube. Using a genetic algorithm-based artificial neural network thermal science: year 2016, vol. 20, No. 1, pp. 53-65.

[13] Rahbar, N., et al. Numerical investigation on flow behavior and energy separation in a micro-scale vortex tube. Thermal science, Year 2015, Vol. 19, No. 2, pp. 619-630.

[14] Ismail Cebeci, Volkan Kirmaci, Umit Topcuoglu. The Effects of Orifice Nozzle Number and Nozzle Made of Polyamide Plastic and Aluminum with Different Inlet Pressures on Heating and Cooling Performance. International Journal of Refrigeration S0140-7007(16)30221-3.

[15] Xue Y, Arjomandi M, Kelso R. The working principle of a vortex tube. International journal of refrigeration 36 (2013) 1730-1740

[16] Majidi D, Alighardashi H, Farhadi F. Best vortex tube cascade for highest thermal separation. International journal of refrigeration 85 (2018) 282-291.

[17] Kumar A, Vivekanand, Subudhi S. Cooling and dehumidification using vortex tube. Applied Thermal Engineering 122 (2017) 181-193. 